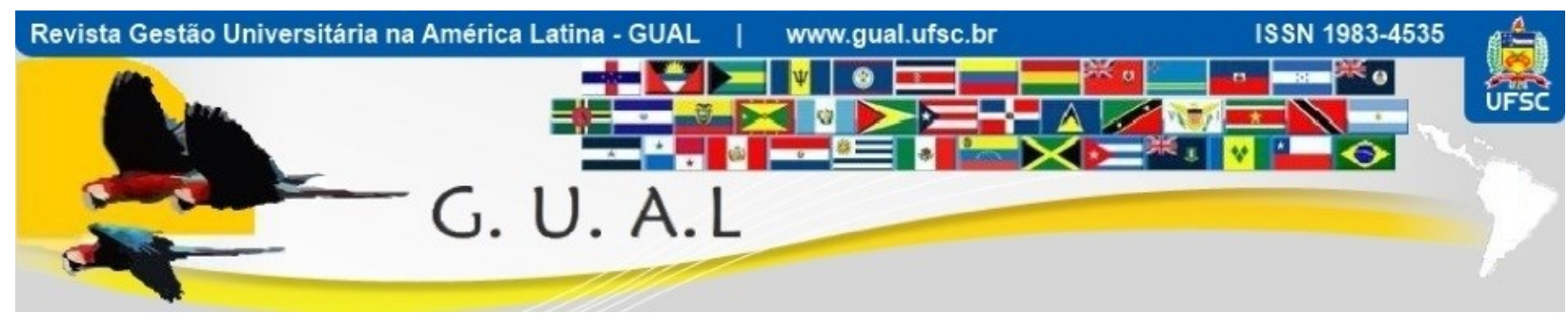

DOI: http://dx.doi.org/10.5007/1983-4535.2016v9n4p167

\title{
O PROJETO EXTENSÃO PRODUTIVA E INOVAÇÃO - PEPI E SUA CONTRIBUIÇÃO PARA O DESENVOLVIMENTO DA REGIÃO DO NOROESTE COLONIAL DO RS
}

\section{THE PROJECT PRODUCTION EXTENSION AND INNOVATION - PEPI AND YOUR CONTRIBUTION TO THE DEVELOPMENT OF THE REGION NORTHWEST COLOGNE OF RS}

\begin{abstract}
Fabiana Baptista Maurer Gomes, Especialista Universidade Regional do Noroeste do Estado do Rio Grande do Sul - UNIJUÍ fabibmg@gmail.com

Marcos Paulo Dhein Griebeler, Doutor Faculdades Integradas de Taquara/RS - FACCAT marcosdhein@faccat.br

Dieter Rugard Siedenberg, Doutor Universidade Regional do Noroeste do Estado do Rio Grande do Sul - UNIJUÍ dieterrs@unijui.edu.br
\end{abstract}

Recebido em 04/dezembro/2015

Aprovado em 14/outubro/2016

Sistema de Avaliação: Double Blind Review

Esta obra está sob uma Licença Creative Commons Atribuição-Uso. 


\title{
O PROJETO EXTENSÃO PRODUTIVA E INOVAÇÃO - PEPI E SUA CONTRIBUIÇÃO PARA O \\ DESENVOLVIMENTO DA REGIÃO DO NOROESTE COLONIAL DO RS \\ DOI: http://dx.doi.org/10.5007/1983-4535.2016v9n4p167
}

\begin{abstract}
RESUMO
Este estudo visa analisar brevemente a interação entre universidade, empresas e governo, instrumentalizado pela execução do Projeto Extensão Produtiva e Inovação - PEPI na Região Noroeste Colonial do Rio Grande do Sul. O principal objetivo do PEPI é o de aumentar a eficiência e competitividade das empresas do ramo industrial, o aumento da produção, do emprego e da renda, como meio para o desenvolvimento dos setores econômicos e das cadeias e arranjos produtivos do Estado e suas regiões. Em linhas gerais, o PEPI NC atendeu entre março de 2012 e julho de 2015, 345 empresas ligadas ao ramo industrial. Com base em autores como Etzkowitz (2009), Nelson e Winter (2006) e Schumpeter (1982), a pesquisa em pauta adotou, com base em Gil (2008), a abordagem qualitativa, além de se caracterizar-se como descritiva, explicativa e como estudo de caso. Os participantes que contribuíram para o estudo foram dois extensionistas e o diretor adjunto da Agência Gaúcha de Desenvolvimento e Promoção do Investimento - AGDI. Em termos práticos, uma vez analisados os dados coletados e relacionados com a teoria, foram propostas algumas ações tanto para a eficácia do PEPI como para uma maior ênfase na relação entre universidade, empresas e governo, tendose como foco principal o desenvolvimento regional.
\end{abstract}

Palavras-chave: Extensão. Interação. Universidade. Empresa. Governo.

\begin{abstract}
This study aims to briefly analyze the interaction between university, companies and government, instrumentalized by the execution of the Project Production Extension and Innovation -.PEPI in the Northwest Region Cologne of Rio Grande do Sul. The principal goal of PEPI is to increase the efficiency and competitiveness of business the industrial sector, increased production, employment and income, as a means for the development of economic sectors and chains and clusters of the state and its regions. In general, the PEPI NC met between March 2012 and July 2015, 345 companies related to the industrial sector. Based on authors like Etzkowitz (2009), Nelson and Winter (2006) and Schumpeter (1982), research on the agenda adopted, based on Gil (2008), the qualitative approach, in addition to be characterized as descriptive, explanatory and as a case study. Participants who contributed to the study were two extension agents and the deputy director of Gaucha Agency for Development and Investment Promotion - AGDI. In practical terms, once analyzed the data collected and related to the theory were proposed some actions both to the effectiveness of PEPI to greater emphasis on the relationship between university, companies and government, having as main focus the regional development.
\end{abstract}

Keywords: Extension. Interaction. University. Company. Government. 


\section{O PROJETO EXTENSÃO PRODUTIVA E INOVAÇÃO - PEPI E SUA CONTRIBUIÇÃO PARA O \\ DESENVOLVIMENTO DA REGIÃO DO NOROESTE COLONIAL DO RS \\ DOI: http://dx.doi.org/10.5007/1983-4535.2016v9n4p167}

\section{INTRODUÇÃO}

Muitas universidades, principalmente de países em desenvolvimento, estão atualmente construído seus recursos de pesquisa, mas ainda não conseguiram capitalizar o conhecimento através de transferências. O aumento das consultorias em escala e em escopo fornece um mecanismo para atingir a autossuficiência da formação de capital acadêmico através de uma unidade que possui a capacidade de identificar e executar projetos maiores do que poderiam ser assumidos individualmente.

Nesse modelo, a consultoria funciona como um braço da unidade ou departamento acadêmico e por isso repassa lucros à unidade acadêmica. De forma alternativa, a empresa de consultoria pode ter sede fora ou na própria universidade e tornar-se uma empresa independente, contratando pesquisadores para projetos específicos e pagando honorários por sua disponibilidade exclusiva. O modelo de consultoria internalizada pode ser exemplicada pelo Projeto Extensão Produtiva e Inovação (PEPI), executado pela Universidade Regional do Noroeste do Estado do Rio Grande do Sul - UNIJUÍ, desde março de 2012.

O principar objetivo do PEPI é o de aumentar a eficiência e competitividade das empresas do ramo industrial, o aumento da produção, do emprego e da renda, como meio para o desenvolvimento dos setores econômicos e das cadeias e arranjos produtivos do Estado e suas regiões. Institucionalizado pela lei N. ${ }^{\circ} 13.839$ de 5 de dezembro de 2011. Em razão disso, este projeto foi lançado a fim de que se pudesse utilizar o recurso de capital humano da universidade para identificar as necessidades tecnológicas da indústria local, e assim fornecer soluções ao governo estadual. Em outras palavras, o papel desse projeto consiste em organizar o conhecimento que reside na universidade e realizar atividades de marketing, contabilidade, administração e outras que os extensionistas julgarem necessárias, com docentes discentes e corpo técnico. Nessa linha, Etknowitz (2013) define que a consultoria acadêmica significa "trabalhar na via oposta de um escritório de transferência tecnológica, pois a consultoria esta em um via oposta, procurando problemas que possam ser resolvidos com capital humano".

O governo gaúcho investiu em uma ampla proposta com vista ao desenvolvimento regional. O projeto conta com recursos do Programa de Apoio à Retomada do Desenvolvimento do Estado do Rio Grande Do Sul, no qual deverão ser aplicados mais de R\$40 milhões, até 2016.

Para tanto, tem-se como objetivos específicos para o estudo, inicialmente (a) identificar a constituição das relações firmadas entre a UNIJUI e as empresas escolhidas no 


\section{O PROJETO EXTENSÃO PRODUTIVA E INOVAÇÃO - PEPI E SUA CONTRIBUIÇÃO PARA O \\ DESENVOLVIMENTO DA REGIÃO DO NOROESTE COLONIAL DO RS \\ DOI: http://dx.doi.org/10.5007/1983-4535.2016v9n4p167}

âmbito do sistema de ensino superior na região do noroeste do estado do Rio Grande do Sul. Além disso, (b) analisar as particularidades da UNIJUI, no que diz respeito ao PEPI, a partir de sua caracterização, no que diz respeito ao seu relacionamento com o setor produtivo. Por fim, tem-se ainda a (c) proposição de algumas ações para a efetividade do projeto junto à Região Noroeste Colonial do Rio Grande do Sul. A seguir, é possível visualizar o mapa dos 11 municípios que compõem a região do COREDE Noroeste Colonial (NC) do Estado do Rio Grande do Sul, acompanhado do número de empresas atendidas em cada município.

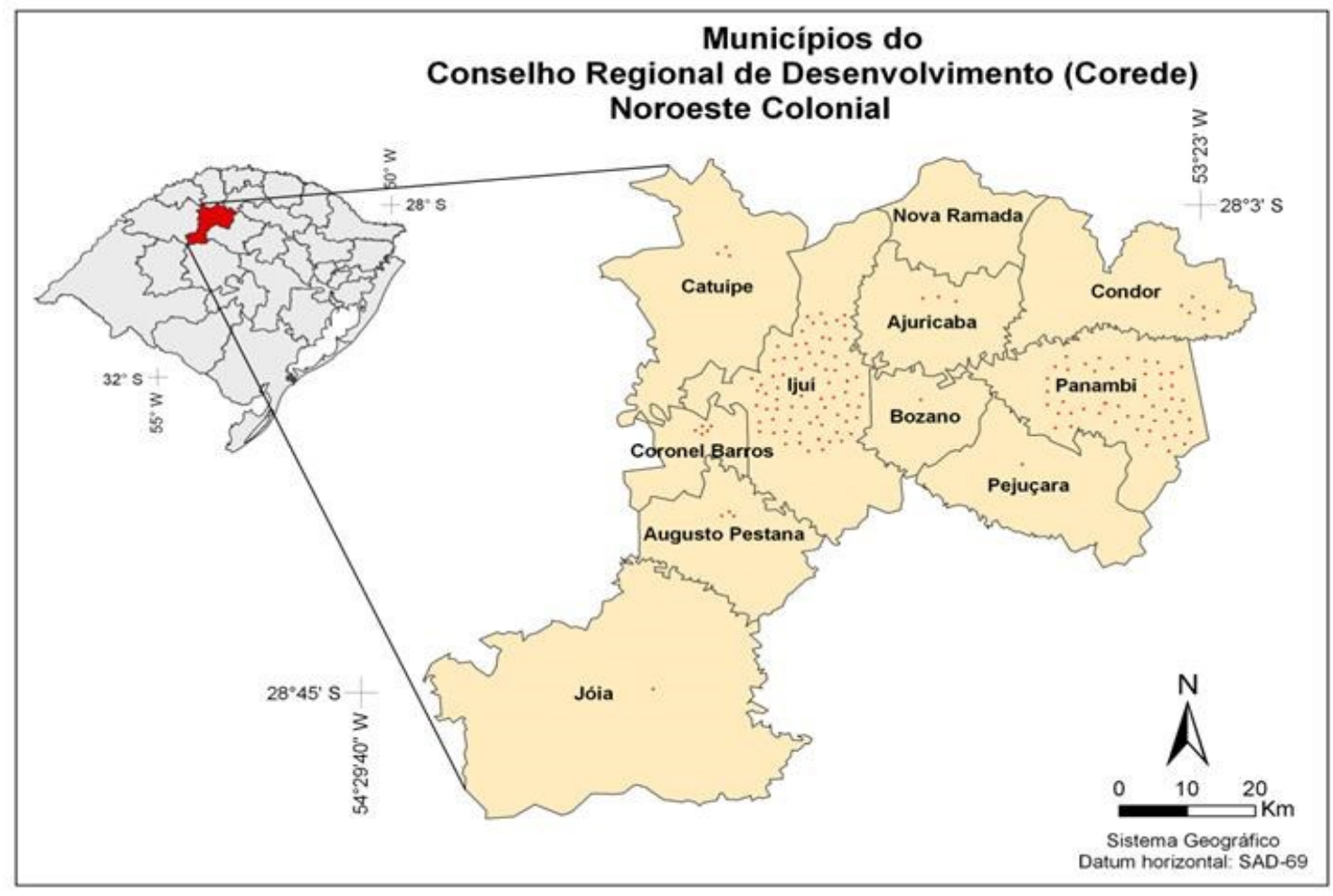

Figura 1 Localização geográfica da RNC.

Fonte: Fundação de Economia e Estatística - FEE, 2008.

Outrossim, vale lembrar que entre março de 2012 e julho de 2015, a equipe do PEPI Núcleo Noroeste Colonial atendeu 345 empresas. Por isso, a fim de reforçar o laço entre universidades, empresa e governo, o artigo tem como objetivo principal compreender a dinâmica institucional do processo de interação Universidade Regional do Noroeste do Estado do Rio Grande do Sul (UNIJUÍ) - PEPI e empresas para o desenvolvimento inovativo na região noroeste do estado do Rio Grande do Sul, frente ao marco cientifico-tecnológico brasileiro. Findada esta breve explanação, parte-se na sequência para a fundamentação teórica que embasou o presente estudo. 


\section{O PROJETO EXTENSÃO PRODUTIVA E INOVAÇÃO - PEPI E SUA CONTRIBUIÇÃO PARA O \\ DESENVOLVIMENTO DA REGIÃO DO NOROESTE COLONIAL DO RS \\ DOI: http://dx.doi.org/10.5007/1983-4535.2016v9n4p167}

\section{FUNDAMENTAÇÃO TEÓRICA}

Os principais fundamentos teóricos que auxiliam na compreensão das interações entre universidade e empresa iniciam-se com uma busca na teoria institucionalista, cuja abordagem se constitui numa das perspectivas deste trabalho. É a estrutura institucional que define, entre outra coisa como se dá a relação entre ciência e tecnologia e inovação. Na sequencia, abordase então a concepção de inovação dentro de uma visão evolucionista, que se insere nesta relação, onde os atores em questão, universidade, empresa e governo possuem papel relevante.

\subsection{TRÍPLICE HÉLICE}

A necessidade de construir uma sociedade fundamentada no conhecimento e difusora de inventos é uma questão de supremacia nacional. O governo brasileiro percebeu isso há algumas décadas e por isso vem criando leis e incentivos para modificar a situação atual da inovação em território nacional. Ele utiliza-se de fundos de financiamento, incentivos fiscais, editais com o setor empresarial e diversos outros setores que são passiveis de inovação.

Entende-se por Sistema Nacional Inovativo (SNI) é o conjunto de regras e procedimentos que incrementam a aquisição, a criação e o uso de conhecimentos imersos na sociedade, tornando a inovação uma ferramenta fundamental para a elaboração de vantagens competitivas. (ETZKOWITZ, 2009). As empresas brasileiras que buscam inovar investem em pesquisa e desenvolvimento $(\mathrm{P} \& \mathrm{D})$, para viabilizar o processo, o governo dispõe de uma série de incentivos e facilidades entre os quais:

A) incentivos fiscais em Pesquisa \& Desenvolvimento;

B) possibilidade de subvenção a projetos considerados importantes para o desenvolvimento tecnológico;

C) subsídio para a fixação de pesquisadores nas empresas;

D) programas de financiamento à inovação de capital empreendedor.

Esses mecanismos buscam facilitar a construção de pontes entre os agentes inovadores, o estado demonstra o objetivo integrar os agentes e diminuir os riscos transacionais dos contratos de transferência de tecnologia. A teoria utilizada para descrever a vinculação entre os sujeitos, estado, universidade e indústria, participantes da construção de um ambiente inovador, será a Tríplice Hélice. A teoria citada trata-se de um modelo espiral de inovação que leva em consideração as múltiplas relações recíprocas, entre os três agentes, 


\section{O PROJETO EXTENSÃO PRODUTIVA E INOVAÇÃO - PEPI E SUA CONTRIBUIÇÃO PARA O \\ DESENVOLVIMENTO DA REGIÃO DO NOROESTE COLONIAL DO RS \\ DOI: http://dx.doi.org/10.5007/1983-4535.2016v9n4p167}

(universidade, empresas e governo), em diferentes estágios do processo de geração e disseminação do conhecimento.

Cada hélice é uma esfera institucional independente, que trabalha em cooperação e interdependência com as demais esferas, através de fluxos de conhecimento entre elas. Além das conexões entre as esferas institucionais e com o amadurecimento do relacionamento entre elas, cada uma assume com o estabelecimento de vínculo, o papel institucional fundamental das outras. Como exemplo disso é possível verificar quando as universidades assumem postura empresarial licenciando patentes e criando empresas de base tecnológicas, enquanto firmas desenvolvem uma dimensão acadêmica, compartilhando conhecimentos entre elas e treinando funcionários em níveis cada vez mais elevados de qualificação. (ETZKOWITZ et al, 2005). O Estado instrumentaliza sistema normativo/legal para intervir e regular as "Hélices", e assim gerar mais dinamismo e velocidade.

A gestão de inovação passa pela construção de novos conhecimentos, onde a universidade representa um papel de criador de novos processos. Se aceita que o conhecimento é passível de ser estimulado e promovido. Para que isso ocorra é necessário estimular a cultura, o comportamento, a autonomia, a criatividade dos sujeitos envolvidos no processo. Porém muitas organizações do setor produtivo esquecem de motivar as pessoas a compartilhar seus conhecimentos, bloqueando assim a capacidade inventiva da própria organização. Esse processo de compartilhamento do conhecimento é chamado de sociabilização do conhecimento, conhecido como processo de experiência compartilhada que cria o conhecimento tácito, como, por exemplo, modelos mentais compartilhados e habilidades técnicas. (CHOO, 2006). O ponto de sociabilização do conhecimento é fundamental, pois só assim é possível disponibilizar aos outros a ideia e o aprimoramento do conhecimento.

O relacionamento proposto pela $\mathrm{TH}$ entre as instituições, não ocorre de forma simples, já que todas pertencem a realidades diferentes. $\mathrm{O}$ instrumento proposto para a diminuição da assimetria da informação é o contrato, (TIMM e GUARISSE, 2012), falam que o contrato é a regulação jurídica (essencialmente estatal) que institui regras, sobre sua formação, execução, nulidade e os direitos das partes. 


\section{O PROJETO EXTENSÃO PRODUTIVA E INOVAÇÃO - PEPI E SUA CONTRIBUIÇÃO PARA O \\ DESENVOLVIMENTO DA REGIÃO DO NOROESTE COLONIAL DO RS \\ DOI: http://dx.doi.org/10.5007/1983-4535.2016v9n4p167}

\subsection{INOVAÇÃO}

O tema inovação é tratado por Schumpeter (1982) é uma referencia importante, por considera-la o elemento dinâmico da atividade econômica e o motor do capitalismo. Para o autor, o desenvolvimento é fruto da realização das novas combinações que significam produzir outras coisas ou as mesmas coisas de maneira diferente, caracterizando-se assim a própria inovação. Assim, ele introduz o conceito de "destruição criadora", onde os elementos anteriores dão lugar a outros elementos que vão gerar a inovação, ou seja, o compete com o antigo e acaba por destruí-lo.

As combinações na seara da inovação englobam cinco combinação conforme Schumpeter: (i) novos produtos: significa a introdução de um novo bem ou de uma nova qualidade em um bem com os quais os consumidores ainda não estejam familiarizados; (ii) novos métodos de produção: caracteriza-se pela introdução de um método que ainda não tenha sido testado pelo ramo de negocio da indústria e que neste sentido seja uma nova descoberta científica ou uma nova forma de manejar comercialmente uma nova mercadoria; (iii) novos mercados: refere-se à abertura de atuação em um espaço particular da indústria que ainda não tenha entrado, tenha este mercado existido antes ou não; (iv) novas matérias-primas ou mesmo bens semimanufaturados, quer tais fontes já existam ou seja criadas; (v) nova organização industrial: relaciona-se a novas configurações na indústria, como a criação de uma posição de monopólio ou mesmo sua fragmentação (SCHUMPETER 1982).

Para Schumpeter (1982) também é creditada a distinção básica entre inovação e invenção, assinalando que "uma invenção é uma ideia, um esboço ou um modelo para um novo ou melhorado artefato, produto, processo ou sistema”, enquanto que uma inovação somente se configura quando há uma transação comercial envolvendo o artefato, produto ou processo em si. Fageberg (2007) discorre que para tornar uma invenção em inovação à empresa precisa combinar diferentes rios de conhecimentos, capacidades, habilidades e recursos, o que normalmente demanda um período considerável de tempo entre dois processos, refletindo o enorme trabalho que existe entre o surgimento das ideias e sua implementação. Para este autor, é preciso compreender o desenvolvimento econômico, o qual deve ser alimentado pela inovação como um processo evolucionário. Com a contribuição dos neo-schumpeterianos ou evolucionários, os estudos acerca da inovação tem proliferado mais recentemente, sobretudo nas ciências sociais e dentro de uma visão multidisciplinar, o que reforça a importância do tratamento da inovação sob diferentes perspectivas. 


\section{O PROJETO EXTENSÃO PRODUTIVA E INOVAÇÃO - PEPI E SUA CONTRIBUIÇÃO PARA O \\ DESENVOLVIMENTO DA REGIÃO DO NOROESTE COLONIAL DO RS \\ DOI: http://dx.doi.org/10.5007/1983-4535.2016v9n4p167}

Nelson e Winter (2006 p.151) acentuam que "a rotina pode referir-se a um padrão repetitivo de atividade numa organização inteira, a uma habilidade individual, ou- como adjetivo- á eficácia regular e sem incidentes de um desempenho organizacional ou individual". Por tanto a rotina assume vários papeis no processo de inovação, dentre os quais os autores citam a rotina como memória da organização, a rotina como trégua, e a rotina como meta no controle da organização, na reprodução das rotinas existentes e na imitação das rotinas empregadas por outras organizações.

\subsection{UNIVERSIDADE E EMPRESA}

O estudo de interação universidade-empresa emergiu como um campo de pesquisa especifica nas três ultimas décadas como parte do aumento de politicas que enfatizam a comercialização da pesquisa e as ligações entre pesquisa básica e necessidades sociais.

Verifica-se que a publicação de estudos neste campo é recente, com expressivo volume entre os anos de 2000 a 2004, demonstrando que suas raízes científicas provem dos campos relacionados à administração de negócios e economia, e transitam pela natureza multidisciplinar destas áreas (TEIXEIRA e MOTA, 2012).

A importância dada ao tema tem gerado um corpo de pesquisa que varia em relação à perspectiva (universidade, empresa, governo), à estrutura (formal, informal), nível de analise (mercado, organização, individuo) e efeito (econômico, acadêmico, institucional, cultural gestão). Os principais temas pesquisados na área apontam para o processo de transferência do conhecimento e como este pode ser influenciado pelas características das empresas, das universidades e dos pesquisadores, também apontam os principais canais que se dá a interação, a importância e a função dos agentes intermediários.

O interesse por esse estudo também é estimulado pelo rápido crescimento das pesquisas relacionadas ao sistema nacional de inovação. Os livros enfatizam a importância das interações e dos arranjos institucionais e neste sentido apresentam-se as universidades como atores que podem contribuir para o desenvolvimento econômico num contexto de economia baseada no conhecimento. Dentro do sistema nacional de inovação as universidades aparecem como agentes que contribuem para o a transferência do conhecimento pra o setor produtivo permitindo assim a aceleração da produção e do conhecimento para a inovação. “As universidades são conhecidas como o repositório dos conhecimentos científicos e 


\section{O PROJETO EXTENSÃO PRODUTIVA E INOVAÇÃO - PEPI E SUA CONTRIBUIÇÃO PARA O \\ DESENVOLVIMENTO DA REGIÃO DO NOROESTE COLONIAL DO RS \\ DOI: http://dx.doi.org/10.5007/1983-4535.2016v9n4p167}

tecnológicos públicos, conhecimentos estes que elas criam e reproduzem através do ensino e vão aumentando põe meio de pesquisa" (NELSON e WINTER, 2006).

Conforme Dagnino (2003), na abordagem da Tríplice Hélice as interações entre universidade e empresas são fruto de um novo contrato social, de uma nova dinâmica na qual seria reservada, a primeira a função de participar mais ativamente no processo de desenvolvimento econômico local". Outra via apresenta o sistema nacional de inovação, pois tem uma visão mais Schumpeteriana e é fortemente fundamentada na teoria de inovação que atribui importância fundamental ao processo inovatico que ocorre na empresa e as relações que se estabelecem entre ela e sue entorno como determinante da competitividade dos países, de forma que a universidade figura como agente entorno para a promoção da competitividade das empresas e da nação. (DAGNINO 2003).

Tanto uma como a outra identificam a universidade como coautora de novas ideias, sempre em parceria com as a empresas, pois ambas as visões defendem o papel ativo que a comercialização é necessária pra construir uma inovação. As duas abordagens também convergem no que diz respeito ao tratamento não linear do processo inovativo (ETZKOWITZ et al, 2005). Faz-se necessário apresentar à primeira politica relevante que ilustra as intenções governamentais. A politica que encoraja a formação de aglomerações regionais econômicas e a formação de spin-offs baseado nas pesquisas acadêmicas, e a segunda viam a politica para estimular as atividades de patenteamento e licenciamento por parte das universidades, gerando assim uma nova empresa, ou uma transferência de tecnologia.

Outro mecanismo utilizado é a criação de instituições pontes para aproximar os dois sujeitos (universidade e empresa), um ambiente neutro para negociação, as chamadas "instituições pontes" que tem como objetivo reduzir a distancia cultural entre as partes já que suas culturas de produção são extremamente distintas. No entanto, a simples criação dessas instituições só fará sentido se a promoção e o engajamento em direção a novos caminhos estiverem comprometido os agentes, pesquisadores e os empresários, de fato.

Por sua vez, Nelson e Winter (2006) acreditam que existem dois caminhos pelos quais as pesquisas acadêmicas alimentam o avanço técnico no setor produtivo: (1) os caos em que a pesquisas geram versões pilotos de projetos que posteriormente o setor produtivo desenvolve e comercializa, ou (2) os casos em que a pesquisas acadêmicas geram conhecimento que permitem o emprego de técnicas pelo setor produtivo com os mais variados propósitos. $\mathrm{O}$ estado da arte do conhecimento gerado pelas universidades configura0se como importante 


\section{O PROJETO EXTENSÃO PRODUTIVA E INOVAÇÃO - PEPI E SUA CONTRIBUIÇÃO PARA O \\ DESENVOLVIMENTO DA REGIÃO DO NOROESTE COLONIAL DO RS \\ DOI: http://dx.doi.org/10.5007/1983-4535.2016v9n4p167}

fonte para novas aplicações tecnológicas nas empresas que se revelam diferentes dos padrões correntes de soluções disponíveis no mercado, permitindo assim o desenvolvimento de tecnologias disruptivas (ZAWISLAK e DALMARCO, 2011).

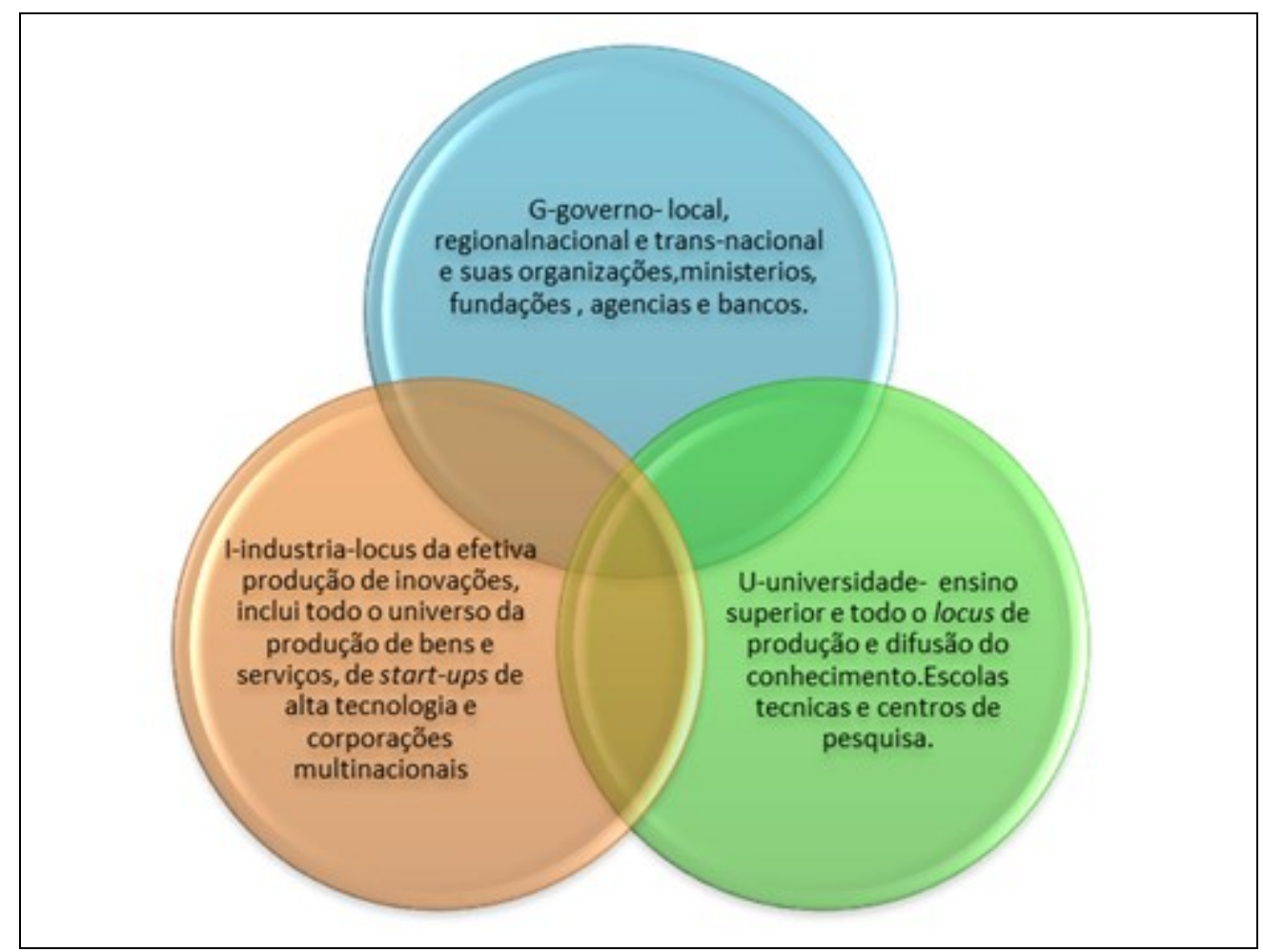

Figura 2 Visualização da tríplice hélice.

Fonte: adaptado pelos autores com base em Etzkowitz (2009).

Para a economia, o conceito de conhecimento esta vinculado ao aprendizado, que foi elaborado a partir de um trabalho de Arrow (1962) o qual está associado a um processo das indústrias que ampliam seus estoques de conhecimento, aperfeiçoam seus procedimentos de busca e refinam suas habilidades em desenvolver ou manufaturar produtos. A integração do conhecimento apresentado pela Tríplice Hélice é visto pela autora como essencial para a construção de uma politica inovativa. A necessidade da integração de múltiplas competências torna o processo de inserção de inovação mais complexo, não só em termos da base de conhecimentos, que necessita ser mobilizada para realizá-lo de forma eficaz, como também em termos dos arranjos organizacionais, necessários para a viabilização da Tríplice Hélice (T.H), (ROTHWELL, 1992). Findada esta breve exposição bibliográfica, parte-se na sequência para a seção metodológica que norteou o presente estudo. 


\section{O PROJETO EXTENSÃO PRODUTIVA E INOVAÇÃO - PEPI E SUA CONTRIBUIÇÃO PARA O \\ DESENVOLVIMENTO DA REGIÃO DO NOROESTE COLONIAL DO RS \\ DOI: http://dx.doi.org/10.5007/1983-4535.2016v9n4p167}

\section{PROCEDIMENTOS METODOLÓGICOS}

A pesquisa em pauta adotou a abordagem qualitativa, por considerar-se mais adequada ao estudo em questão que é a dinâmica institucional do processo de interação entre universidade, empresas e governo, permitindo que se estabelecesse uma compreensão analítico-reflexiva capaz de revelar com maior profundidade a realidade do PEPI, na região noroeste colonial. Sobre este aspecto, Flick (2009) acrescenta que de forma diferente da pesquisa quantitativa a abordagem qualitativa considera a comunicação do pesquisador com o campo e seus membros como parte explicita da produção de conhecimento, ao invés de exclui-la como variável intermediária. Neste caso, consideraram-se como parte do processo de pesquisa as subjetividades do pesquisador e dos atores que são parte do processo de pesquisa.

Gil (2008) observa que as pesquisas podem ser exploratórias, descritivas, explicativas e Vergara (2009) acrescenta ainda à metodológica, aplicada e intervencionista. As pesquisas exploratórias buscam sistematizar informações, conceitos e ideias que possam sustentar estudos posteriores em uma investigação mais ampla. As pesquisas descritivas visam descrever as características de determina população ou fenômeno ou ainda estabelecer correlações entre as variáveis, enquanto que as pesquisas explicativas procuram justamente identificar os elementos que contribuem para a ocorrência de determinado fenômeno. A pesquisa metodológica, por sua vez se refere à construção de instrumentos ou procedimentos para entendimento da realidade.

A pesquisa aplicada objetiva a resolução de problemas concretos, de finalidade prática. Por fim, a pesquisa intervencionista visa principalmente intervir na realidade estudada para modifica-la. Dentro desta perspectiva a pesquisa aqui realizada caracteriza-se por ser descritiva e explicativa. É descritiva porque procurou descrever a partir de categorias de analise como estão fundamentadas as interações entre universidades e empresas. E ainda é explicativa porque buscou apontar as razões que caracterizam o padrão de interação entre o PEPI, e os empresários do noroeste coloquial do estado do Rio Grande do Sul.

Quanto aos meios de investigação ou procedimentos empregados, Gil (2008) e Vergara (2009) assumem que a pesquisa pode se configurar em diversos tipos, dentre qual esta pesquisa em particular tomou a forma de pesquisa bibliográfica, com a formação um a base teórica que sustentou o problema e facilitou a interpretação dos dados pesquisados e também como pesquisa documental uma vez que foram utilizados documentos produzidos 


\section{O PROJETO EXTENSÃO PRODUTIVA E INOVAÇÃO - PEPI E SUA CONTRIBUIÇÃO PARA O DESENVOLVIMENTO DA REGIÃO DO NOROESTE COLONIAL DO RS \\ DOI: http://dx.doi.org/10.5007/1983-4535.2016v9n4p167}

pela UNIJUI, tais como relatórios de gestão e de atividades, planejamentos estratégicos, dentre outros.

Também se caracterizou como estudo de caso, o que envolve a investigação detalhada e profunda de um ou mais objetos de estudo. As fontes de dados utilizadas na pesquisa se constituem tanto de dados primários como de dados secundários. Com relação ao tipo de corte de acordo com Viera (2004) trata-se de uma pesquisa seccional com perspectiva longitudinal, uma vez que a coleta de dados foi feita num determinado momento, mas resgatando informações de períodos passados que pudessem contribuir para a compreensão do objeto de estudo. Já os formatos de coleta de dados foram desenhados a partir dos quadros dos objetivos específicos da pesquisa.

\begin{tabular}{|c|c|}
\hline Objetivos específicos & Metodologia \\
\hline $\begin{array}{l}\text { (i) Descrever a evolução do marco científico } \\
\text { tecnológico, do projeto Pepi, na região do estado do } \\
\text { Rio Grande do Sul. }\end{array}$ & $\begin{array}{l}\text { Pesquisa documental; } \\
\text { Pesquisa bibliográfica. }\end{array}$ \\
\hline $\begin{array}{l}\text { (ii) Analisar a constituição das relações firmadas } \\
\text { entre a UNIJUI e as empresas escolhidas no âmbito } \\
\text { do sistema de ensino superior na região do noroeste } \\
\text { do estado do Rio Grande do Sul, em face do projeto } \\
\text { PEPI. }\end{array}$ & $\begin{array}{l}\text { Pesquisa de dados secundários na base de dados do } \\
\text { PEPI-NC; } \\
\text { Estudo exploratório pesquisa de campo entrevista } \\
\text { com os extensionistas, com o diretor adjunto da } \\
\text { AGDI. }\end{array}$ \\
\hline $\begin{array}{l}\text { (iii) Analisar as particularidades da UNIJUI, no } \\
\text { que diz respeito ao Pepi, a partir de sua } \\
\text { caracterização e seu relacionamento com o setor } \\
\text { produtivo. }\end{array}$ & $\begin{array}{l}\text { Pesquisa de dados secundários na base de dados do } \\
\text { PEPI-NC; } \\
\text { Estudo exploratório pesquisa de campo com os } \\
\text { extensionistas e com os empresários, com } \\
\text { relacionamento com o PEPI-NC. }\end{array}$ \\
\hline
\end{tabular}

Quadro 1 Objetivos Específicos e Metodologia.

Fonte: Elaborado pelos autores, 2015.

Para realização do primeiro objetivo, foram utilizadas fontes secundarias, por meio de pesquisa bibliográfica e documental. A pesquisa bibliográfica constitui no levantamento de livros e artigos que relacionam o estudo aqui propostos. Já a pesquisa documental constitui na consulta a documentos complementares às referencias bibliográficas, tais como Programas e planos de ação do governo do estado do Rio Grande do Sul.

Com relação ao segundo objetivo, também foram utilizadas fontes de dados secundários, coletados na base de dados do PEPI-NC, e a coleta de dados primários por questionários semi estruturados com os extensionistas, e com o diretor adjunto responsável por participar como agente do governo do estado na realização do projeto. Todos os questionários foram enviados por meio eletrônico. Já para o terceiro objetivo, também foram utilizadas fontes de dados secundários, na coleta de dados do PEPI-NC, e a coleta de dados 


\section{O PROJETO EXTENSÃO PRODUTIVA E INOVAÇÃO - PEPI E SUA CONTRIBUIÇÃO PARA O \\ DESENVOLVIMENTO DA REGIÃO DO NOROESTE COLONIAL DO RS \\ DOI: http://dx.doi.org/10.5007/1983-4535.2016v9n4p167}

primários por questionários semi estruturados com os extencionistas e com empresários atendidos pelo projeto PEPI-NC. Todos os questionários foram enviados por meio eletrônico, sendo eles respondidos entre os meses de outubro e dezembro de 2014.

Em se tratando de uma pesquisa qualitativa, considerou-se adequado proceder a análise e interpretação dos dados por meio da analise de conteúdo. Neste sentido, foi utilizado como unidade de registro para a análise frases e orações dos questionários semi estruturados. Tais citações foram utilizadas individualmente e combinadas entre si e também analisadas segundo a unidade de contexto, que permite considerar o contexto no qual o dado analisando foi produzindo. A categorização constitui-se num procedimento básicos da analise de conteúdo e consistente justamente na classificação de elementos a partir de critérios previamente definidos, formando as categorias que são rubicas e classes, que reúnem um grupo de elementos, sob um titulo genérico, agrupamento esse efetuado em razão dos caracteres comum destes elementos (BARDIN, 2004). Com base nisso, tem-se a seguir a análise dos resultados obtidos.

\section{O PROJETO EXTENSÃO PRODUTIVA E INOVAÇÃO - PEPI E SUA CONTRIBUIÇÃO PARA O DESENVOLVIMENTO DA REGIÃO DO NOROESTE COLONIAL DO RS}

Neste capítulo serão contextualizados dois questionários semiestruturados sendo que um deles foi realizado com o Diretor Ajunto de Produção da Agência Gaúcha de Desenvolvimento e Promoção do Investimento - AGDI e o outro foi realizado com extensionistas do que participam do Projeto Extensão Produtiva e Inovação - PEPI na Região Noroeste Colonial desde março de 2012 (início do projeto).

Importante frisar que a parceria entre o governo do Estado do Rio Grande do Sul e a Universidade auxilia a tornar o desenvolvimento regional uma realidade, bem como auxilia na consecução dos objetivos estratégicos da própria universidade cumprindo o seu papel de instituição comunitária. Em outras palavras, visa reforçar o papel da excelência acadêmica dos programas de ensino, de pesquisa e de extensão e dos serviços integrados com o mundo do trabalho, contribuindo para com o desenvolvimento regional e para a qualidade de vida dos cidadãos por meio da formação de profissionais qualificados e capazes de interagir na construção de diversos aspectos da realidade.

A unidade organizacional do Projeto Extensão Produtiva e Inovação são compostas por 3 níveis, o estratégico, o tático e o operacional. O estratégico é formado pela Diretoria de 


\section{O PROJETO EXTENSÃO PRODUTIVA E INOVAÇÃO - PEPI E SUA CONTRIBUIÇÃO PARA O \\ DESENVOLVIMENTO DA REGIÃO DO NOROESTE COLONIAL DO RS \\ DOI: http://dx.doi.org/10.5007/1983-4535.2016v9n4p167}

Produção e Inovação (DPI), e subordinado diretamente, a essa diretoria, porem fazendo parte do mesmo nível vem o Comitê de Coordenação. Os agentes que fazem parte da Diretoria de Produção e Inovação fazem parte do estado do Rio Grande do Sul, mais propriamente a agência Gaúcha de Desenvolvimento e promoção do Investimento, a AGDI. Esta diretoria tem como objetivo geral ser o executor das politicas publica de desenvolvimento socioeconômico do estado, formulando e executando projetos visando o fortalecimento, agregação de valor de renda, e eficiência coletiva das cadeias, sistemas e arranjos produtivos locais (APL), no RS. Da mesma forma, visa buscar o maior equilíbrio regional no desenvolvimento socioeconômico.

Com isso, o Governo do Estado do RS ampliar seu papel público de promotor do desenvolvimento. Atua em sistema com seus órgãos e se relaciona com instituições publicas e privadas criando um ambiente propício ao desenvolvimento de empresas trabalhador e da sociedade. Em tempos em que as finanças se sobrepõem a produção e ao emprego, em que as crises corroem as sociedades e produção desenfreada consome o planeta, afirmar politicas publica agregadoras de valor, renda e emprego são reafirmar o desenvolvimento sustentável com uma necessidade essencial à vida humana.

Neste contexto, os municípios e os pequenos empreendimentos são a base para um novo modelo de desenvolvimento do país, capaz de gerar desenvolvimento com a geração de emprego, distribuição de renda e inclusão social, uma vez que a economia é impulsionada por pessoas arrojadas que dão vida a um estabelecimento comercial e industrial. É importante ressaltar nesse processo que as lideranças e as administrações municipais devem criar um ambiente favorável às empresas, pois é inviável pensar em municípios sustentáveis do ponto de vista econômico e social se esses empreendimentos não estiverem num circulo virtuoso de prosperidade e geração de oportunidades para as pessoas da comunidade.

Em termos práticos, a metodologia utilizada para a execução das ações do PEPI tem como princípio a engenharia de processos de negócios (EPN) que compõem a cadeia de valor agregado (value added chain, VAC), foi utilizada a metodologia ARIS (Archietecture of intergrated information systems). A cadeia de valor agregado (VAC) apresenta as funções da empresa que agregam valor ao produto, além disto, define a sequencia em que cada uma das etapas deverá ocorrer. Cada etapa do VAC, por sua vez, foi desmembrada em EPCs (Event Driven Process Chain), que indica cada atividade que deve ser realizada para conclusão de 


\section{O PROJETO EXTENSÃO PRODUTIVA E INOVAÇÃO - PEPI E SUA CONTRIBUIÇÃO PARA O DESENVOLVIMENTO DA REGIÃO DO NOROESTE COLONIAL DO RS \\ DOI: http://dx.doi.org/10.5007/1983-4535.2016v9n4p167}

determinada etapa, bem como os responsáveis por realizar estas atividades e os documentos que serão utilizados para suporta-las.

Em termos operacionais, parte-se a seguir para a exposição e breve análise das questões aplicadas aos sujeitos da pesquisa, mencionados na seção antetior. Por isso, inicialmente entrevistou-se o Diretor Adjunto da AGDI. Quando questionado sobre seu olher sobre as mudanças observadas pela agência na Região Noroeste Colonial a partir da execução do PEPI, o Diretor da AGDI evidência que:

O Projeto Extensão Produtiva e Inovação pretende aumentar a eficiência e a
competitividade das empresas com o consequente aumento da renda e emprego.
Todavia, medir isto, continua sendo um desafio para a própria agencia razão pela
quais muitos resultados são apresentados de forma qualitativa com base em certo
empirismo. O próprio Núcleo do Projeto na região através da publicação: Projeto
Extensão Produtiva e Inovação - PEPI: Um ano de atuação na Região Noroeste
Colonial do Rio Grande do Sul - Relatos e Perspectivas, afirma que "a atuação do
PEPI proporcionou as empresas atendidas mudanças operacionais e estruturais, na
forma de interagir com o cliente e de buscar soluções inovadoras através de novas
relações com instituições de ensino, pesquisa e de treinamentos". Empresa com um
grau avançado de maturidade organizacional pode busca novas formas de inovação.
Com relação à inovação notou-se que ela ocorre de uma forma ainda não plenamente
estruturada. Com raras exceções, a inovação na região é dependente da ação de
empresas líder do setor ou da exigência do mercado. Falta à região a cultura
inovadora, capacitações para inovação e métodos inovadores, algumas dessas
demanda foi buscada em outras instituições através do PEPI.

As proposições teóricas decorrentes do modelo da Tríplice Hélice de Etzkowitz que referência às relações entre as três esferas, universidade, governo e empresas em um processo evolutivo são referenciados como suporte ao estudo de interação. Do ponto de vista da universidade, configura-se uma "segunda revolução acadêmica", onde incorpora este agente como parte da missão o desenvolvimento econômico local. Firma-se uma pareceria entre a universidade e a sociedade, a qual impõe à instituição de ensino uma participação mais ativa no processo de desenvolvimento, o que caracteriza a "terceira missão" (DAGNINO, 2003, ETZKOWITZ et al, 2005).

Estas novas teorias trazem em tela a ideia da universidade empreendedora que integra o desenvolvimento econômico dentro da universidade como mais uma função além da tradicional de ensino e pesquisa (ETZKOWITZ et al, 2005). Enquanto a concepção da Tríplice hélice reforça o papel da universidade empreendedora e a sua participação no desenvolvimento nacional, a abordagem do sistema nacional de inovação enfatiza o papel das interseções das universidades com as empresas para o processo inovativo. A abordagem deste sistema dá foco ás empresas existentes e ao motor da inovação, com outras organizações 


\title{
O PROJETO EXTENSÃO PRODUTIVA E INOVAÇÃO - PEPI E SUA CONTRIBUIÇÃO PARA O DESENVOLVIMENTO DA REGIÃO DO NOROESTE COLONIAL DO RS \\ DOI: http://dx.doi.org/10.5007/1983-4535.2016v9n4p167
}

funcionando como uma estrutura de suporte. $\mathrm{O}$ foco da tríplice hélice é a interação entre a universidade e a empresa e o governo e a criação de organizações hibridam como as incubadoras para apoiar a estruturação de novas empresas (ETZKOWITZ et al, 2005).

Além disso, sabe-se que o PEPI - Núcleo Noroeste Colonial, tem operacionalizado o projeto junto às empresas desde março de 2012. Desta forma com base nesta realidade a sua visão sobre o papel da inovação no desenvolvimento desta região pelo diretor da AGDI é exposta a seguir.

\begin{abstract}
Uma vez considerado os limites das avaliações sobre a inovação é preciso dizer que a região tem a segunda colocação nominal do total de ações de inovação do Projeto no Estado, estando atrás apenas da região da Serra. Em relação ao total de ações propostas a região ocupa a quarta colocação no estado. Lembrando que estamos tratando sempre de 20 Núcleos Regionais que cobrem o estado todo.

Novamente cotejando as observações dessa AGDI com os resultados que o próprio Núcleo Regional demonstrou na publicação acima referida, temos que de um total de 50 inovações observadas, 43 delas $(86 \%)$ podem ser classificadas como incrementais e sete (14\%) como inovações radicais. O Núcleo observou ainda que $74 \%$, ou seja, 37 organizações possuíam a inovação com abrangência limitada ao ambiente interno, inovando ao comprar máquinas e/ou equipamentos. As inovações para o mercado representavam 20\% (10 empresas). Já as Inovações de âmbito global foram apresentadas em apenas 6\% (3 empresas) das empresas. Após analisar os questionários respondidos, verificou-se também que das 50 empresas que inovaram 7 se concentravam em produtos, 7 em processo, 8 em serviços, 14 em marketing e 14 inovaram no setor organizacional.
\end{abstract}

Foi nos anos 80 que muitos países implementaram politicas para fortalecer a interação entre as universidades e as empresas de forma a alcançar um melhor desempenho econômico tendo como suporte a pesquisa acadêmica, o que em muitos casos envolveram mudanças de legislação, criando assim vias jurídicas que propiciavam uma interação assegurada pelo governo. (FELDMAN 2011). Desta forma tem aumentado muito a pressão das agencias financiadoras publicas para que os pesquisadores acadêmicos engajarem-se em projetos com parceiros empresaria, deixando claro que o estado tem como finalidade o desenvolvimento das pesquisas no meio comercial (VASQUES 2010).

Por isso, a partir da implementação do PEPI na região, o projeto apresenta tanto limites quanto possibilidades, tal como observa o diretor da AGDI, conforme seu depoimento a seguir.

A AGDI concorda com as análises de que o que se tem na região é uma dependência
por parte da grande maioria das empresas da inovação e das decisões de empresas
líderes. Essa análise já estava retratada na publicação Plano de Desenvolvimento do
APL Metalmecânico Pós-Colheita - Panambi e Condor 2012-2022 que foi apoiado
pela AGDI e que demonstra que mesmo entre as empresas consideradas líderes há
uma subdivisão entre as que têm elevada capacidade de investimento, de inovação e
de desenvolvimento tecnológico e as que têm limitada capacidade de investimento.
Acreditamos que é justamente nestas últimas e também nas demais que não são 


\title{
O PROJETO EXTENSÃO PRODUTIVA E INOVAÇÃO - PEPI E SUA CONTRIBUIÇÃO PARA O DESENVOLVIMENTO DA REGIÃO DO NOROESTE COLONIAL DO RS \\ DOI: http://dx.doi.org/10.5007/1983-4535.2016v9n4p167
}

líderes e que acabam tendo a mesma dificuldade que o PEPI pode atuar através do fortalecimento do que chamamos de Rede de Oferta de Serviços Tecnológicos. O PEPI ao diagnosticar individualmente as necessidades da empresa, possibilita quando esse conjunto de informações individuais é extrapolado - que as instituições que oferecem serviços possam melhor programar e utilizar laboratórios e pesquisadores, além de permitir que ações de fomento estatais à inovação possam ser mais bem direcionadas.

Ao apontar quais foram as melhorias organizacional das empresas atendidas pelo PEPI-NC desde março de 2012, tendo como foco a competitividade, o diretor da AGDI destaca que,

É possível ser afirmativo nessa questão, ainda que estejamos sempre de certa forma limitados a percepção da evolução que tem inicialmente o próprio empresário e posteriormente o extensionista. Ao longo da execução do projeto tentamos criar algumas métricas que fossem capazes de dar respostas mais quantitativas a todos estes questionamentos. Isso só está sendo possível neste momento com a finalização do subprojeto de Benchmarking Internacional cujo questionário tem forte ênfase na inovação e no aumento da competitividade.

Neste sentido, o Benchmarking, tem dois grandes objetivos: i) Comparar as empresas do estado do Rio Grande do Sul com as suas congêneres internacionais e; ii) Avaliar o impacto do Programa, comparando as empresas que recebem apoio dos extensionistas e aquelas que não recebem.

Por sua parte de entrevistado, ao final do questionário foi disponibilizado um espaço para que o mesmo pudesse expressar algum comentário, o qual foi corroborado pelo diretor da AGDI.

\begin{abstract}
Acreditamos que no momento (dezembro de 2014) em que o Projeto Extensão Produtiva e Inovação atinge cerca de 4.000 empresas atendidas e/ou em atendimento que as informações reunidas através do que chamamos de "Radar de Investimento", bem como o conjunto de dados agregados de todos os núcleos, constituem uma fonte riquíssima de informações para o planejar do conjunto das instituições que formam a rede de oferta de serviços tecnológicos a empresas. Acessar e trabalhar as informações deste banco é a chave em "código aberto", disponível para quem quiser contribuir para o desenvolvimento do Rio Grande do Sul. É neste sentido, que avaliamos o Projeto no Estado. Ou seja, primeiramente ele atende as necessidades individuais das empresas que por ele passaram, mas, essas uma reunidas de forma agregada constituem um pelo instrumento de planejamento para o aumento da eficiência e competitividade que vão assegurar o crescimento da renda e do emprego do conjunto de empreendimentos atingidos pelo Projeto.
\end{abstract}

A estrutura organizacional é uma forma de agrupar as pessoas de uma determinada organização em certas unidades. Esta estrutura pode ser divida em diferentes Unidades Organizacionais (UO), cujo objetivo central é reunir atividades e/ou cargos que possuem determinado objetivo em comum. Com esse agrupamento é possível utilizar recursos de organização de maneira eficiente, além de garantir aos funcionários em certa identidade na organização. 


\section{O PROJETO EXTENSÃO PRODUTIVA E INOVAÇÃO - PEPI E SUA CONTRIBUIÇÃO PARA O DESENVOLVIMENTO DA REGIÃO DO NOROESTE COLONIAL DO RS DOI: http://dx.doi.org/10.5007/1983-4535.2016v9n4p167}

É importante definir para cada uma das unidades organizacionais o seu papel dentro do sistema como um todo. A definição do papel organizacional, por sua vez, não deve ser entendida como uma listagem das atividades que previstas para cada individuo, como uma lista de tarefas. A definição de uma estrutura organizacional deve ser vista como algo mais orgânico, uma vez que um individua com determinado cargo pode desempenhar diferentes papais dentro da organização. Para a descrição destes papeis, é indispensável definir os resultados esperados e as responsabilidades dos diversos papeis organizacionais.

Em razão disso, no que se refere as respostas dos extensionistas que executam o projeto junto aos empresários foi possível coletar as informações que serão descritas a seguir. Inicialmente, quanto ao questionamento sobre a adesão do empresário ao projeto, o entrevistado A destaca que isto se dá devido "a visualização da oportunidade de receber assessoria e capacitações de profissionais capacitados em gestão, processos e inovação".

O entrevistado B aponta que

O empresário participa do projeto a partir do momento que compreende a proposta do Projeto, entende seus objetivos e se compromete com o mesmo. Também pela oportunidade de obter de forma gratuita auxílio de profissionais capacitados em diferentes áreas que irão auxiliar a empresa a executar melhorias em sua gestão. (ENTREVISTADO B)

Para a eficácia do projeto, questionou-se quais são os parâmetros utilizados para que isto seja possível. Nesse sentido, o extensionista entrevistado expõe que o

Posicionamento dos empresários quando à inovação e a possibilidade de planejamento para que a mesma seja sistemática e incremental. O empresário consegue visualizar a inovação como projeto. Melhorias no processo com o mapeamento e cronometragem dos tempos. O planejamento organizacional com a análise estratégica possibilitando melhorias e direcionamento junto o mercado. (ENTREVISTADO A)

Como outro questionamento, pautou-se ainda sobre a temática da inovação, ou seja, se este item era facilmente aplicado/vivenviado pelas empresas atendidas, além de saber como as propostas de mudança na rotina dos empresários são acatadas. Pelos depoimentos dos dois extensionistas, verifica-se este é ainda um processo desafiador.

\footnotetext{
A aplicação da inovação nunca é fácil em nenhuma empresa, pelo PEPI as empresas são capacitadas a assessoradas, a planejar e gerir o processo para inovação. Mudança de rotina também não é aceito facilmente isso e regra geral, para todas as empresas. Nada é fácil quando se trata de inovação, as empresas estão preocupadas em produzir e melhorar processo. Quando é proposto inovações sempre existe resistência. (ENTREVISTADO A)
} 


\title{
O PROJETO EXTENSÃO PRODUTIVA E INOVAÇÃO - PEPI E SUA CONTRIBUIÇÃO PARA O

\begin{abstract}
A inovação depende de um processo de maturação das empresas e ainda não está sendo aplicadas na maioria das empresas, muitas necessitam de capacitação nesta área. Quanto à proposta de mudança, é sempre bem vinda, mas cabe ao extensionista juntamente com o empresário avaliar o que é mais importante para empresa em determinado momento e período, pois os planos de ação propostos são montados juntamente com o empresário, com base no diagnóstico realizado e na opinião do empresário. (ENTREVISTADO B)
\end{abstract}

Como se pode perceber, a inovação depende não apenas de orientação como também do conhecimento e das competências das instituições e da população local geradoras de externalidades econômicas. O conhecimento, a cultura, os serviços e principalmente, a capacitação em gerar novos conhecimentos, são fatores econômicos pertencentes ao território capazes de proporcionar ganhos econômicos para suas empresas. São geradores de desenvolvimento local na medida em que as empresas se apropriam destes ganhos. Outrossim, ao ser interrogado sobre as principais mudanças observadas e ocorridas, o extencionista apontou que dentre elas merece destaque a

\begin{abstract}
mudança cultural e desmistificação da inovação como algo instantâneo (eureka), agora as empresas possuem conhecimento da necessidade do planejamento e gestão para inovação, da importância de cada fase, assim como da manutenção de um banco de dados do projeto. Algumas possuem dificuldades na aplicação metodologia outras são menos resistentes, desenvolvem produtos e dedicam tempo à inovação. Mas no geral podemos a forma estrutural das empresas dificulta o processo inovativo. (ENTREVISTADO A)
\end{abstract}

Por fim, o entrevistado B expõe que “As principais mudanças são percebidas na forma de gerir a empresa, muitas passam a adotar controles, métodos de custos, processos produtivos que antes não faziam parte da rotina empresarial e que aos poucos é inserido no dia a dia da gestão”.

Como se pode perceber, com base no referencial teórico e nos depoimentos coletados, o Estado participa com o apoio de incentivos fiscais e subsidiários, através de bolsas e encontros com a comunidade. Enquanto isso, a universidade entra com a capacidade de abordar problemas e necessidades da sociedade de forma mais ampla, construindo bases para novos projetos de pesquisa e de paradigmas intelectuais, criando um circulo virtuoso com um desenvolvimento intelectual.

Além de oferecer novas ideias às empresas envolvidas o PEPI, busca-se por meio de sua rede acadêmica as capacidades de pesquisa e de ensino, em áreas especificas e necessárias de cada ambiente produtivo, a fim de melhorar e de avançar a prestação de serviços à empresa, ou criar novos meios de capitalizar o conhecimento gerado dentro da universidade. 


\section{O PROJETO EXTENSÃO PRODUTIVA E INOVAÇÃO - PEPI E SUA CONTRIBUIÇÃO PARA O \\ DESENVOLVIMENTO DA REGIÃO DO NOROESTE COLONIAL DO RS \\ DOI: http://dx.doi.org/10.5007/1983-4535.2016v9n4p167}

Desta maneira, tem-se como proposição de um conjunto de ações, três atividades consideradas como fundamentais para a eficácia do projeto na Região Noroeste Colonial. Por primeiro, publicizar os resultados em termos de avanços em termo de melhoria proposta pelos extensionistas junto às empresas, a fim de reforçar os laços entre essas organizações e o Governo do Estado e a Universidade, uma vez que as atividades desepenhadas impactam na comunidade regional. Em segundo, realizar oficinas que abordem a temática da inovação para que as empresas possam melhor aproveitar tanto seu capital humano como também contribuir para a eficácia organizacional. Por terceiro, criar um conjunto de indicadores que abarquem temas coligados à inovação, tais como Produção Mais Limpa, prática (ou não) de Benchmarking, produtividade, lançamento de novos produtos/serviços, absenteísmo e vendas, dentre outros temas.

Entende-se que a adoção deste conjunto de fatores pode contribuir não apenas para as empresas, à universidade e ao governo, mas principalmente, para que seja garantida a promoção do desenvolvimento regional, instrumentalizado por parcerias como esta executada pela Unijuí pelo PEPI NC.

\section{CONSIDERAÇÕES FINAIS}

O Extensionismo ou a prática de extensão pode ser visto como o meio que estabelece a relação da universidade e da sociedade a fim de que possam se manifestar, tendo como ponto de referência as atividades que o universitarismo (sujeito que estende papel da universidade à comunidade), e se propõe a realizar cuidando daquelas que, efetivamente, contribuem para o progresso e das funções que essas atividades vão ter dentro do social vigente. Os resultados esperados pela AGDI, para com o PEPI são a operacionalização da metodologia do projeto construído pela agencia estatal na região da universidade conveniada. E este resultado se torna evidente em razão dos números, ou seja, pelas suas 345 empresas ligadas ao ramo industrial e existente nos 11 municípios que integram a Região Noroeste Colonial.

Outrossim, para total eficiência do PEPI, este deverá apoiar as empresas no planejamento para investimentos futuros para buscar a expansão de capacidades, e ampliação da atuação no mercado. Estimular a implantação de inovação dentro das empresas cadastradas e estimular a execução do plano de gerenciamento de resíduos sólidos (art. 21 da lei 12.305/2010), manter sempre que contrato com a empresa as responsabilidades como a confiabilidade e o sigilo dos atendimentos, e por fim estimular as empresas quanto à 
importância da contratação de serviços produtivos e tecnológicos de instituições ofertantes e programas públicos.

Com base nisso, entende-se que existem uma ampla gama de atividades que consistem em um grande desafio e simultaneamente, uma oportunidade de crescimento e de desenvolvimento, tanto para empresas como para a universidade e para o Governo do Estado do RS.

\section{REFERÊNCIAS}

ARROW. Kenneth, A chapter in The Rate and Direction of Inventive Activity: Economic and Social Factors, 1962, p. 609-626.

BARDIN, L. Análise de conteúdo. Edições. Portugal, Lisboa: Edições 70, 2004.

LEI No 12.305, DE 2 DE AGOSTO DE 2010. Institui a Política Nacional de Resíduos Sólidos; altera a Lei ${ }^{0} 9.605$, de 12 de fevereiro de 1998; e dá outras providências http://www.planalto.gov.br/ccivil_03/_ato2007-2010/2010/lei/112305.htm. Acesso: 23 Mai 2015.

CHOO, Chun Wei, A organização do conhecimento: como as organizações usam a informação para criar significado, construir conhecimento e tomar decisões. São Paulo: 2006.

DAGNINO, R. A interação universidade-empresa no Brasil e o "argumento da hélice tripla”. Revista Brasileira de Inovação, v. 2, n. 2, p. 267-307, jul/dez.2003.

ETZKOWITZ, Henry. Hélice tríplice: universidade-indústria-governo - inovação em movimento. Porto Alegre: EDIPUCRS, 2009.

ETZKOWITZ, Henry et al. Towards "meta-innovation" in Brazil: the evolution of the incubator and the emergence of a triple helix. Research Policy, v.34, p.411-424, 2005.

FLICK, U. Introdução à pesquisa qualitativa. Porto Alegre: Artmed, 2009.

GIL, A. C. Métodos e técnicas de pesquisa social. São Paulo: Atlas, 2008.

NELSON, R. R.; WINTER, S. G. Uma teoria evolucionária da mudança econômica. Campinas: Editora da Unicamp, 2006.

ROTHWELL, R. Sucessful industrial innovation: critical factors for the 1990s. R\&D Management, v. 22, n. 3, p. 221-240, 1992.

SCHUMPETER, J. A. Teoria do desenvolvimento econômico: uma investigação sobre lucros, capital, crédito, juro e ciclo econômico. São Paulo: Abril Cultural, 1982. 
TEIXEIRA, A. A. C.; MOTA, L. A bibliometric portrait of the evolution, scientific roots and influence of the literature on university - industry links. Rev. Scientometrics, v.93, p.719-743, 2012.

VERGARA S. C. Projetos e relatórios de pesquisa em administração. São Paulo: Atlas, 2009.

ZAWISLAK, P. A.; DALMARCO, G. The silent run: new issues and outcomes for university-industry relations in Brazil. Journal of Technology Management \& Innovation, v. 6, n.2, p. 66-82, 2011. 